\title{
A Case of Arrhythmogenic Right Ventricular Dysplasia with Atrial Flutter
}

\author{
Yuji Nakazato, M.D., Yasuro NaKaTa, M.D., \\ Takashi ToKano, M.D., Yasuhiko OHNo, M.D., \\ Teruhiko HisaOKa, M.D., Masataka SumiYoshi, M.D., \\ Shunsuke Ogura, M.D., Hiroshi Yamaguchi, M.D., \\ Sachio Kawal, M.D., ${ }^{*}$ Ryozo OKada, M.D., ${ }^{*}$ \\ and Nobutane Hazato, M.D.**
}

\section{SuMmary}

A 57-year-old male who had arrhythmogenic right ventricular dysplasia (ARVD) with recurrent atrial flutter (AF) is reported. The patient had more frequent episodes of AF than of ventricular arrhythmias. Magnetic resonance imaging, cchocardiography and right ventriculography revealed dilatation of the right ventricle and endomyocardial biopsy specimens from the right ventricle showed findings which were compatible with ARVD. The left ventricular specimen, however, also revealed a loss of myocytes and interstitial fibroelastic changes. The present case demonstrates an overlap of post-inflammatory or primary endomyocardial fibroelastic changes with ARVD. (Jpn Heart J 35: $689-694,1994)$

Key words: Right ventricular dysplasia Fatty infiltration Endocardial fibroelastosis

\begin{abstract}
RRHYTHMOGENIC right ventricular dysplasia (ARVD) is a disorder characterized by fatty and fibrotic replacement of the right ventricular myocardium in association with ventricular tachycardia (VT) ${ }^{1)}$ In a few patients with ARVD, pathologic lesions may involve the left ventricle or the atrium. ${ }^{2-4)}$ In addition, other arrhythmias, including sinus node dysfunction and atrioventricular block, have been reported. ${ }^{5,6)}$ Supraventricular arrhythmias often occur in ARVD despite antiarrhythmic therapy. ${ }^{7}$ We report a case of ARVD with slow atrial flutter and infrequent episodes of ventricular arrhythmias.
\end{abstract}

From Division of Cardiology, Department of Internal Medicine, *Research Laboratory for Cardiovascular Pathology, Juntendo University School of Medicine, Tokyo, Japan, and **Department of Cardiology, Koshigaya Municipal Hospital, Saitama, Japan.

Address for correspondence: Yuji Nakazato, M.D., Division of Cardiology, Department of Internal Medicine, Juntendo University School of Medicine, 2-1-1, Hongo, Bunkyo-ku, Tokyo 113, Japan.

Received for publication March 14, 1994.

Accepted May 9, 1994. 


\section{Case Report}

A 57-year-old male was admitted to our hospital with a chief complaint of recurrent palpitations. The patient had suffered from this symptom for 10 years despite treatment with several antiarrhythmic drugs. The patient's brother had died suddenly during athletic exertion at 26 years of age. At the time of admission, the patient's blood pressure was $144 / 88 \mathrm{mmHg}$, and the heart rate was 80 beats per minute (bpm). No abnormal physical findings were noted. Laboratory examination was unremarkable. Chest roentgenogram showed a cardiothoracic ratio of $49 \%$.

The electrocardiogram (ECG) showed regular sinus rhythm with a rate of $72 \mathrm{bpm}$. Tall $\mathrm{R}$ waves in lead $\mathrm{V}_{1}$, inversion of $\mathrm{T}$ waves in leads II, III, aVf, and $\mathrm{V}_{1}-\mathrm{V}_{6}$, intraventricular conduction disturbance, and prominent post excitation (Epsilon) waves were noted (Figure 1A). During a palpitation attack, slow atrial flutter with various degrees of ventricular conduction was observed (Figure 1B). Holter ECG revealed sporadic ventricular extrasystoles, suggestive of a right ventricular origin, but no sustained VT was documented on repeated recordings. A signal-averaged ECG showed a markedly prolonged, filtered QRS duration (197 msec) and decreased root mean square voltage $(11.2 \mu \mathrm{V}$ ).

Echocardiography demonstrated marked dilatation of the right ventricle

A

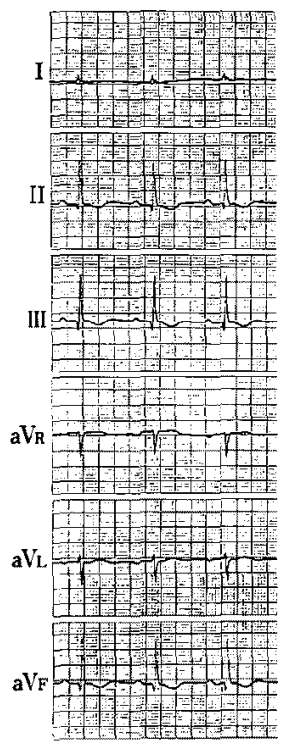

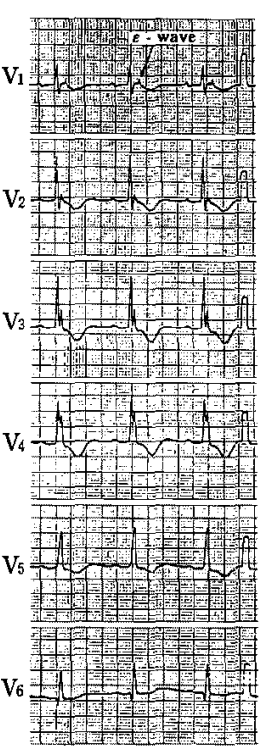

B

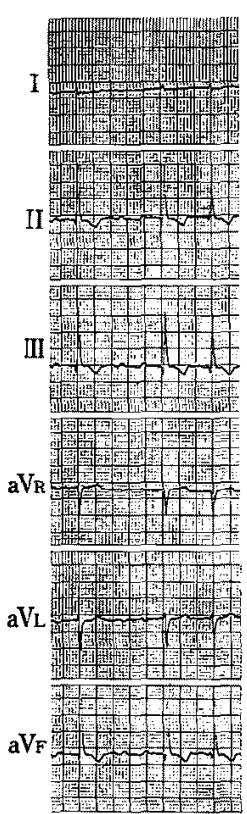

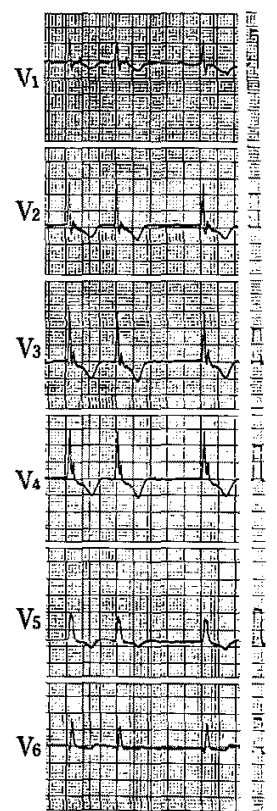

Figure 1. A: Prominent post-excitation waves are seen during the asymptomatic ECG. B: Atrial flutter was observed on the EGG during a palpitation attack. 


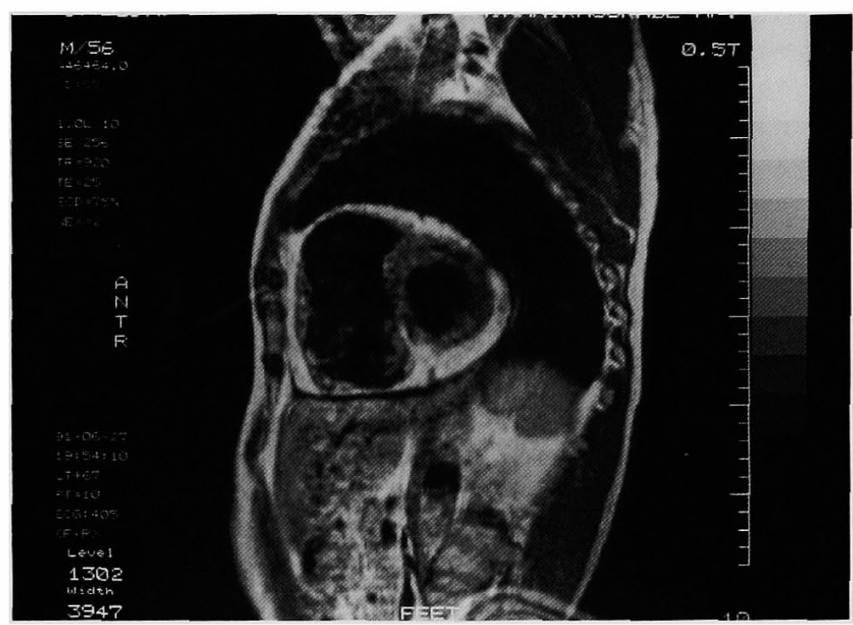

Figure 2. Magnetic resonance imaging of the heart showed marked dilatation of the right ventricle.

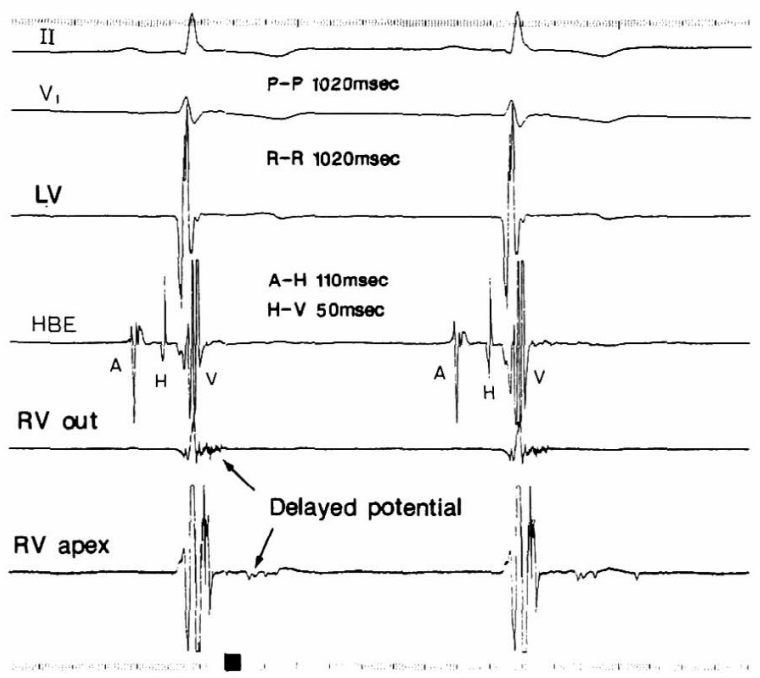

Figure 3. Intracardiac catheter mapping of the right ventricle showed delayed potentials at the site of the apex and outflow tract.

with abnormal hypertrophy of the trabeculae and mild hypertrophy of the left ventricle with normal contraction. The right atrium was slightly enlarged, but the left atrium was of normal size. Magnetic resonance imaging (MRI) also showed a markedly dilated right ventricle (Figure 2). Coronary angiography revealed no obstructive lesions; right ventriculogram revealed marked dilatation and diffuse loss of contractile function.

Endomyocardial catheter mapping was performed during sinus rhythm. 
A

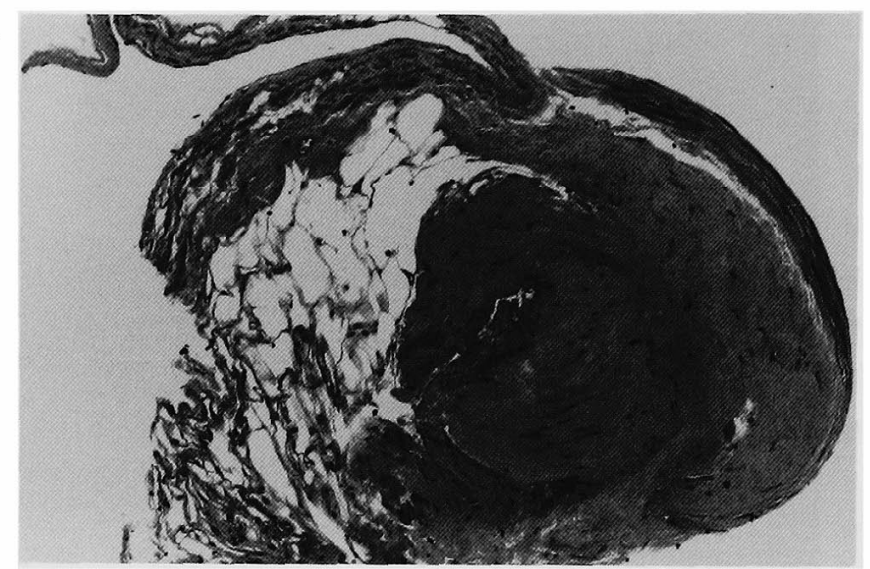

B

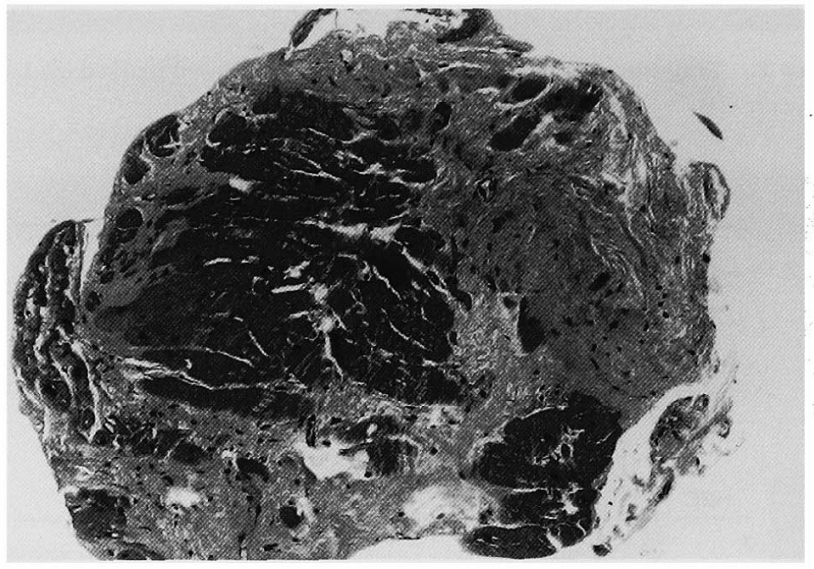

Figure 4. A: Endocardial biopsy from the RV revealed moderate fibroelastic thickening of the endocardium and severe fibrosis of the subendocardium with partial fatty infiltration (Hematoxylin-Eosin stain, $\times 150$ ). B: This biopsy specimen from the left ventricle showed prominent interstitial fibrosis (Hematoxylin-Eosin stain, $\times 150$ ).

Delayed potentials in the apex and outflow tract of the right ventricle were noted (Figure 3). Sinus node function and atrioventricular conduction time were within normal limits. Double ventricular premature stimuli from the right ventricular apex and outflow tract failed to induce any repetitive response. Atrial premature stimulation was also unable to induce any clinical tachycardia at the time of study.

Endocardial biopsies were performed on both the right and left ventricles. Specimens from the right ventricle showed moderate to severe fibroelastic thickening of the endocardium and severe fibrosis of the subendocardium with partial fatty infiltration (Figure 4A). In the posterior wall of the left ventricle, a loss of myocytes and prominent interstitial fibrosis were observed (Figure 4B).

After administration of pilsicainide $(150 \mathrm{mg} /$ day $)$, the incidence of atrial 
flutter was markedly decreased.

\section{Discussion}

In most cases of ARVD, VT is commonly observed," and other clinical arrhythmias are also seen..$^{2-4)}$ However, few descriptions of supraventricular arrhythmias in ARVD exist.") Tonet et $\mathrm{al}^{7}$ ) have reported the incidence of supraventricular tachycardia in ARVD seen in 17 of 72 patients (24\%) in spite of antiarrhythmic therapy. In addition, right atrial enlargement was found in 5 of 12 patients $(42 \%)$ examined by echocardiogram. They have suggested that enlargement of the right atrium or a right atrial abnormality, or both, might be the mechanism of supraventricular arrhythmias in ARVD.

In our case, atrial flutter presented as the main symptomatic arrhythmia. Although a biopsy of the atrium was not obtained, atrial involvement with the lesions noted above could be the genesis of atrial flutter in this patient. Secondary changes brought on by enlargement of the right atrium could also play a role in the development of atrial arrhythmias as suggested by Tonet et al. ${ }^{\text {) }}$ Although the sporadic occurrence of extrasytoles originating from the right ventricle was observed in this case, sustained VT was not documented by repeated Holter recordings. It is not surprising that several patients with ARVD have had only ventricular premature beats. ${ }^{8}$ Sustained VT may eventually develop with progression of the pathologic lesions.

Mild fatty infiltration with endomyocardial fibroelastosis compatible with ARVD was seen in this case. The endomyocardial fibroelastosis with hypertrophy was also noted in the left ventricle. Fibroelastic lesions of both ventricles could occur as the result of diffuse inflammation or as a primary endomyocardial fibrosis. Lobo et $\mathrm{a}^{9)}$ have described the pathologic features of 13 cases of ARVD, including 10 necropsy hearts, 1 explant heart, and 2 partial right ventricular resections. They found three patterns of histologic change: (1) right ventricle markedly thinned, epicardium and endocardium contiguous with virtually no intervening tissue; (2) normal wall thickness or slightly thinned, myocardium almost totally replaced by fat; and (3) normal or thin wall, myocardium largely replaced by fat with scattered residual myocardial cells and fibrous tissue. Although endocardial fibroelastosis was present in only eight cases; it was found in each of these three patterns and occasionally in the left ventricle. In this case, the presence of endocardial fibroelastosis in the LV could explain the extensive degree of ARVD; however, it remains unclear whether the endocardial fibroelastosis means the coexistence of ARVD and post-inflammatory changes. It is difficult to make a definite diagnosis at present only by the limited biopsy materials. Further experience, including examination of autopsy materials, is nec- 
essary for clarifying the pathogenesis of ARVD.

\section{References}

1. Marcus FI, Fontaine GH, Guiraudon G, Frank R, Laurenceau JL, Malergue C, Grogogeat Y: Right ventricular dysplasia; a report of 24 adult cases. Circulation 65: 384, 1982

2. Webb JG, Kerr CR, Huckell VF, Mizgala HF, Ricci DR: Left ventricular abnormalities in arrhythmogenic right ventricular dysplasia. Am J Cardiol 58: 568, 1986

3. Pinamonti B, Sinagra G, Salvi A, Di Lenarda A, Morgera T, Silvestri F, Bussani R, Camerini F: Left ventricular involvement in right ventricular dysplasia. Am Heart J 123: 711, 1992

4. Belhassen B, Shapira I, Hammerman C: Unusual manifestation of arrhythmogenic right ventricular dysplasia as ventricular fibrillation, atrial paralysis, and hypoexcitable right ventricle. Br Heart J 59: 263, 1988

5. Rossi P, Massumi A, Gillet P, Hall RJ: Arrhythmogenic right ventricular dysplasia; clinical features, diagnostic technique, and current management. An Heart J 103: 415, 1982

6. Beerman LB, Zuberbuhler JR, Neches WH, Fischer DR, Fricker FJ, Mathews RA, Park SC, Lenox CC: Arrhythmogenic right ventricular dysplasia associated with atrioventricular conduction disturbance. Am J Cardiol 52: 909, 1983

7. Tonet JL, Miranda RC, Iwa T, Poulain F, Frank R, Fontaine GH: Frequency of supraventricular tachyarrhythmias in arrhythmogenic right ventricular dysplasia. Am J Cardiol 67: 1153, 1991

8. Sabel KG, Blomstrom-Lundqvist C, Olsson SB, Enestrom S: Arrhythmogenic right ventricular dysplasia in brother and sister; is it related to myocarditis? Pediatr Cardiol 11: 113, 1990

9. Lobo FV, Heggtveit HA, Butany J, Silver MD, Edwards JE: Right ventricular dysplasia: Morphological findings in 13 cases. Can J Cardiol 8: 261, 1992 